Felipe Sánchez Reyes

Pedro C. Tapia Zúñiga

\title{
La hechicera de Teócrito
}

Hijo de Praxágoras y de Filina, Teócrito nació en la isla de Siracusa; no se sabe exactamente cuándo, y se ignora también el año de su muerte. En el escolio a su poema 4, se dice que durante la Olimpiada 124 (284-281 a. C.) él estaba en sus mejores tiempos; ${ }^{1}$ sin embargo, los peritos discuten estas fechas. Las conjeturas sobre el año de su nacimiento fluctúan entre el 315 y el 300 , pero casi todos están de acuerdo en que el año 260 a. C. fue el último de su vida. ${ }^{2}$

No se sabe cómo ni cuándo llegó Teócrito a Alejandría y se ganó la protección de Tolomeo II; lo cierto es que llegó poe$\mathrm{ta}_{0}{ }^{3}$ y que también al final de sus días estuvo al sur del Asia Menor, en la isla de Cos, donde siguió escribiendo y, quizá, fijó la redacción definitiva de sus poemas. De la obra de Teócrito, sin hablar de los epigramas, sólo nos llegó una colección de 31 poemas conocida con el nombre de Idilios, es decir, pequeños poemas sueltos; actualmente, todos están de acuerdo

${ }^{1}$ Las fuentes directas para la vida de Teócrito son la Suda, s.v.; la Antologia Palatina, IX, 434 y el escolio correspondiente, así como la propia obra literaria de Teócrito.

${ }^{2}$ Para mayor información, sobre todo bibliográfica, véase R. Keydell, en Kl. $P$., s.v. Theocritos (1).

${ }^{3}$ Según se infiere de su poema 16 , dedicado a Hierón II, Teócrito ya había comenzado a escribir en Siracusa. 
en que tales poemas ni son todos de Teócrito, ni preponderantemente bucólicos: los poemas son mimos (bucólicas, entre ellos), epilios mitológicos, encomios y poesías en metros líricos, de manera que la etiqueta de "bucólico" que lleva este poeta, no es muy adecuada. ${ }^{4}$ Según A. Dihle, entre los poetas de la época helenística, sólo hay uno que, por su potencia creadora, buen gusto y habilidad técnica, puede colocarse al lado de Calímaco: Teócrito de Siracusa. ${ }^{5}$

La palabra "mimo" originalmente quiere decir imitador, actor, imitación; sólo posteriormente ${ }^{6}$ se usó para designar un subgénero literario que incluyera los poemas de Sofrón (siglo $v$ a. C.). Se define, quizá a partir de Teofrasto, como una imitación que se refiere tanto a lo permitido como a lo imperdonable de la vida. Agregar que se trata de una imitación "literaria" significa avanzar siglos en la historia del mimo que, originado en Sicilia, trae la marca del humor pesado y del sentido realista de la vida de sus habitantes. ${ }^{7}$ Mediante la estilización literaria de esta dramática popular, Teócrito creó un género literario que respondía a gustos estéticos exigentes: el mimo que, tomando los mismos temas populares y cotidianos, se sirvió del hexámetro de la épica. Aunque se discute, lo más seguro es que los mimos de Teócrito no estaban destinados a su representación, sino a una simple lectura.

Entre los mimos de Teócrito se encuentran el poema 15 (Las siracusanas), el 7 (Las talisias) y el 2 (La hechicera); estos dos últimos, según dicen los críticos, son sus creaciones más originales. El 7 es famoso, no sólo por su ambiente bucó-

${ }^{4}$ Cf. Herwig Görgemanns, Die griechische Literatur in Text und Darstellung, Band 4: Hellenismus, Stuttgart, Reclam, 1985, p. 49.

${ }^{5}$ Albrecht Dihle, Griechische Literaturgeschichte (von Homer bis zum Hellenismus), Darmstadt, Verlag C.H. Beck, 1992, p. 309 (en inglés, A History of Greek Literature... (tr. by Clare Krojzl), London and New York, Routledge, 1994). Cf. H. Görgemanns, ib., p. 47: Teócrito, "quien, al lado de Calímaco, es el representante más influyente y representativo de esta tendencia literaria [innovadora y erudita]".

${ }^{6}$ Cf. Aristóteles, Poética, 1457b 10.

${ }^{7}$ Cf. Vretska, en Kl. P., s.y. Mimus. 
lico, sino por el "retrato" que el autor hace de sí mișmo bajo el personaje de Simíquides; se ignora qué poeta esté bajo el nombre de su interlocutor Lícides. Quizá, tras Lícides se oculta el poeta Dosiadas, que compuso El altar, un poema figurado (cf. A. P., 15.26) que hace referencia a otro de Teócrito del mismo estilo, conocido como La siringa. ${ }^{8}$ Dado su profundo sentimiento de la naturaleza y la atmósfera bucólica que caracteriza a algunos de sus poemas, se ha supuesto que Teócrito no nació en la ciudad, sino en algún pueblecito o campiña de la jurisdicción de Siracusa. Por ello, un amor al campo como el suyo, dice Wilamowitz, no podía esperarse de Calímaco, pero se nota en Aristófanes y, sin duda, es la fuente que inspira las Bucólicas de Virgilio.?

Sobre el idilio 2, La hechicera, casi todo es incierto; el título mismo, su lugar y fecha de composición son un misterio. Se discute si se llamó La hechicera o Las hechiceras, ${ }^{10}$ no se sabe si fue escrito en Cos o en Alejandría, y sólo se supone que fue uno de sus últimos poemas, escrito en Cos, ya que Delfis es mindio, es decir, de la ciudad de Mindos, situada frente a Cos, y el nombre de Filino puede corresponder a uno de los habitantes de Cos enlistados entre los vencedores olímpicos de los años 264-260. Lo único cierto es que nadie ha negado en serio su autenticidad, aunque se discute su mayor o menor dependencia de un poema de Sofrón con personajes y tema semejante: Las conjuradoras de la Luna.

En este ensayo presentamos en español La hechicera de Teócrito. No tenemos como objetivo un comentario gramatical; por ello, la traducción no quiere ser literal, ni verso a verso, lo cual, creemos, no nos impide ni una ni otra cosa donde ello nos ha parecido conveniente a nuestro objetivo.

${ }^{8}$ Cf. Wilamowitz, M., Hellenistische Dichtung in der Zeit des Kallimachos, Berlin, Weidmannsche Buchhandlung, 1924, II, p. 138; Wilamowitz habla de Dosiades de Creta; cf. M. von Albrecht, en Kl. P., s.v. Dosiades.

${ }^{9}$ Cf. Wilamowitz, M., ib., II, p. 137.

${ }^{10}$ Sobre el tema, cf., Ateneo, XI 475, y Sérvio, ad Verg., Eçl.; VIII 1. 
Tampoco queremos, como algunos de los antiguos romanos, competir con el original. ${ }^{11}$ Basados en el poema del alejandrino, intentamos un poema en español, pero escrupulosamente apegado al sentido del texto y a las connotaciones de sus elementos, sobre todo de los mágicos; ${ }^{12}$ intentamos un poema rítmico y atento a nuestra sintaxis que, si recurre al hipérbaton, no es por respeto a la sintaxis de Teócrito, sino en búsqueda de alguna expresión poética (?) y, sobre todo, por las exigencias de su metro.

El poema se tradujo en heptadecasílabos compuestos: no más de 17 sílabas por verso, como en el hexámetro, $\mathrm{y}$, como es casi normal en estos versos, con dos cesuras obligatorias (en español, se evita la sinalefa entre colon y colon): una después del heptasílabo, y otra, después del primer pentasílabo. Claro que pudimos recurrir a versos libres, pero... ¿qué es verso libre? ¿Por qué hoy, a fuerza, versos libres? Si se usan en función de lo poético, ¿por qué no, y por lo mismo, recurrir al metro y a un ritmo menos caprichoso? Por supuesto, no pensamos que Teócrito lo hubiera hecho así en español: ${ }^{13}$ lo que creemos es que Teócrito, hablando español, pudo haber escrito su poema en una forma semejante. Si nos equivocamos, nostra maxima culpa. El lector dirá si logramos nuestro objetivo. ${ }^{14}$

11 Cf. Hans J., Vermeer, Skizzen zu einer Geschichte der Translation, Frankfurt, Verlag für interkulturelle Kommunikation (IKO), 1992, pp. 209 ss.

12 En Felipe de Jesús Ricardo Sánchez Reyes, "EI idilio II de Teócrito: introducción, traducción y notas", México, UNAM, Facultad de Filosofia y Letras, 1994 (tesis de licenciatura), pp. 122-182, está el índice de todas las palabras que Teócrito usa en este poema, y que sirvió de base para esta traducción.

13 Para otras traducciones al español de este idilio de Teócrito, cf. Bucólicos griegos (traducción y notas de Ipandro Acaico, pról. de Carlos Montemayor), México, Cien del Mundo, SEP, 1984; Danae Frangos Mayorga, "Los idilios de Teócrito", México, UNAM, Facultad de Filosofia y Letras, 1963 (tesis de maestría); Teócrito, Idilios (nueva versión, noticias y notas de Antonio González Laso), Madrid, Aguilar, 1973 (reimpr.), y Bucólicos griegos, ed. de Máximo Brioso Sánchez, Madrid, Akal, 1986, pp. 65-72.

14 Esta traducción está hecha a partir del texto griego editado por Gow, A. S. F., Theocritus (edited with a translation and commentary), Cambridge Univesity Press, 1973 (reimpr.), vol. I, pp. 16-28. 
¿Dónde están mis laureles? ¡Tráelos, Testilis! ¿Dónde, mis filtros? Con la más fina lana roja de oveja ciñe el caldero, porque pienso embrujar al hombre amado que es mi tormento:

hoy hace doce días, desde que el pérfido no me visita, ni ha venido a informarse si ya morimos o estamos vivas, ni a mis puertas llamó, iqué desalmado! Ciertamente Eros y Afrodita se fueron lejos llevando su amor voluble. Para verlo, mañana, yo a la palestra de Timageto voy y pienso increparle tantas vilezas que hace conmigo. Ahora, voy a embrujarlo sahumando inciensos. ¡Vamos, alumbra, 10 Luna, con gran fulgor! Diosa, en voz baja voy a invocarte, y a Hécate también, la subterránea, que incluso perros temen, cuando ella marcha por tumbas muertas y en negra sangre: Hécate horrenda, salve; por esta noche sénos propicia, haciendo estos venenos nada inferiores a esos de Circe ni a los de Perimeda, la rubia aquélla, ni al de Medea. Ave de amor, al joven aquel arrastra tú hasta mi casa. Se consume, primero, cebada en fuego. ¡Pronto, Testilis, mísera, vierte granos! ¿Qué tonterías andas pensando? ¿Acaso tú también, gran desdichada, de mí te burlas?

Vierte y repite a un tiempo: "de Delfis, ahora vierto los huesos". Ave de amor, al joven aquel arrastra tú hasta mi casa. Me hizo sufrir mi Delfis; ahora, por Delfis quemo laureles; y como éstos con ruido mucho crepitan al incendiarse, al instante se extinguen y ni cenizas de ellos miramos,

del mismo modo Delfis, sí, consumiera su carne en llamas.

Ave de amor, al joven aquel arrastra tú hasta mi casa.

Voy a quemar salvado. Diosa Artemisa, mover podrías las férreas puertas de Hades, incluso habiendo cualquier cerrojo. ¡Testilis, ya las perras aúllan en la urbe por nuestra magia; 30 la diosa está en los cruces de las vías; pronto, tañe tú el bronce! Ave de amor, al joven aquel arrastra tú hasta mi casa. Oye, la mar se calla, callan incluso todos los vientos; sin embargo, no calla mi amarga pena dentro del pecho, 
sino que me ardo toda por culpa de ese que hizo que fuera infeliz, miserable, ya no más virgen, y no su esposa. Ave de amor, al joven aquel arrastra tú hasta mi casa. Como yo, con la diosa derrito aquí este céreo muñeco, así, de amor y pronto se derritiera Delfis el mindio; como el rombo de bronce da muchas vueltas por Afrodita, así, aquel hombre muchas vueltas se diera frente a mis puertas. Ave de amor, al joven aquel arrastra tú hasta mi casa. Tres veces vierto vino, también tres veces digo, señora: "si se acuesta en su lecho cualquier doncella, cualquier mancebo, que un olvido terrible los borre justo como Teseo olvidó en Naxos, dicen, antaño a Ariadna, de bellos rizos". Ave de amor, al joven aquel arrastra tú hasta mi casa. Hay una planta arcadia, muy lujuriosa, por cuyo efecto en el monte enloquečen todas las potras y ágiles yeguas; así yo viera a Delfis, y así a mi casa, vuelto un demente, al salir de la asidua palestra untuosa, se regresara. Ave de amor, al joven aquel arrastra tú hasta mi casa. Esta franja inferior del manto suyo perdió mi Delfis; ahora, haciéndola trizas, al fuego cruel yo se la arrojo. ¡Ay, Amor doloroso! ¿Por qué adherido, cual sanguijuela palustre, me has sorbido toda mi negra sangre del cuerpo? Ave de amor, al joven aquel arrastra tú hasta mi casa. Triturando un lagarto, fuerte brebaje llevo mañana; pero ahora, Testilis, tú toma y suave frota estas hierbas sobre el umbral de aquél, mientras serena reina la noche, y siniestra murmura: "de Delfis ahora froto los huesos". Ave de amor, al joven aquel arrastra tú hasta mi casa. ¿Desde dónde, mi amor voy a llorar, hoy que estoy sola? ¿Por dónde doy inicio? ¿Quién me acarreó tal infortunio? Nuestra Anaxo, de Eubulo la hija, pasaba llevando el cesto 65 de Artemisa al santuario; por ésta entonces, fieras diversas (una leona entre ellas) iban en marcha con el cortejo. Diva Luna, mi historia de amor explica dónde comienza. Mi querida Teomaris, nodriza tracia, que en paz descanse, cuyo aposento estaba junto a mi puerta, vino a rogarme y a insistirme que viera también el rito; yo desdichada, 
con mi túnica hermosa de suave lino me fui con ella, circundada del manto que me prestara mi fiel Clearista.

Diva Luna, mi historia de amor explica dónde comienza.

Ya yendo donde habita Licón, en medio del recorrido, vi a Delfis y a Eudamipo que andando iban uno con otro; ellos tenían la barba más esplendente que el helicriso y mucho más fulgentes que tú, Selene, sus torsos eran cual si el bello ejercicio de su gimnasio recién dejaran.

Diva Luna, mi historia de amor explica dónde comienza.

Nada más fue mirarlo, loca me puse; mi pobre pecho se encendió por un fuego, ya mi belleza se marchitaba; no me importó ya nada la procesión, ni supe cómo torné de nuevo a casa; desde ese instante, yo estuve enferma de un malestar ferviente; me fui a la cama diez días enteros. Diva Luna, mi historia de amor explica dónde comienza. El color de mi piel gualda se puso como la hierba; de mi testa el cabello caía sin gracia; lo demás sólo eran pellejo y huesos. ¿A quién no fuimos en pos de ayuda? ¿O cuál casa de anciana sabia en conjuros, pasé por alto? Mas no hallaba sosiego; dábase el tiempo prisa en fugarse. Diva Luna, mi historia de amor explica dónde comienza. $\mathrm{Y}$, así, dije a mi esclava la verdad pura de esta mi historia: "anda, 'Testilis, busca para mi fuerte mal un remedio. Infeliz de mí, toda me tiene el mindio. Vamos, marchando hasta aquella palestra de Timageto, ponte al acecho; va allí todos los días, y allí le agrada pasarse el tiempo. Diva Luna, mi historia de amor explica dónde comienza. Cuando veas que esté solo, discretamente Ilámalo y dile: 'Simeta quiere hablarte'; con mucha astucia tráelo a mi lado". 100 Así dije, marchóse, pronto a mi casa condujo a Delfis de esplendente figura. Fue todo a un tiempo: cuando lo vimos dando vuelta al umbral de nuestra puerta con ágil paso, diva Luna, mi historia de amor explica dónde comienza, 105 me quedé toda fría, más que la nieve; sobre mi frente un sudor me brotaba, como perladas gotas de lluvia; nada podía emitir, ni, por lo menos, cuanto en el sueño balbucean las criaturas, cuando a su madre querida invocan; 
Diva Luna, mi historia de amor explica dónde comienza. Tras mirarme el odioso, clavando el rostro fijo en el suelo, se sentaba en la cama; ya acomodado, tales decía: "me ganaste, Simeta, no cabe duda, como hace poco yo le gané a Filino, que es el más hábil en las carreras: antes que yo a la casa tuya llegara, tú me invitaste. Diva Luna, mi historia de amor explica dónde comienza. Pues habría yo venido. ¡Juro por Eros! Sí, habría venido con dos o tres amigos al caer la noche de suave arrullo, trayendo de Dionisos unas manzanas bajo mi manto y ciñendo en las sienes, entretejida con rojas cintas, una guirnalda de álamo, sagrado árbol del gran Heracles. Diva Luna, mi historia de amor explica dónde comienza. Si acogido me hubieras, bello habría sido (pues ciertamente, entre todos los jóvenes, veloz y bello, soy afamado); con sólo haber besado tu hermosa boca yo habría dormido; si a otra parte me hubieras corrido y trancas tu puerta hubiera, habrían venido a ustedes hachas y teas de todos lados. Diva Luna, mi historia de amor explica dónde comienza. Ahora afirmo que debo rendirle gracias primero a Cipris, y después de esta diosa, mujer, a ti; tú, la segunda, al traerme a tu casa me retiraste casi incendiado de esa pasión ardiente, pues a menudo prende una flama Eros, mucho más fuerte que la del mismo Líparo Hefesto; diva Luna, mi historia de amor explica dónde comienza, con perversas pasiones, hizo que huyera de su aposento, una virgen, o alguna recién casada, dejando tibia de su esposo la cama". Dijo estas cosas; yo, la muy tonta, aferrada a su mano, sobre el mullido lecho lo atraje; y pronto, un cuerpo en otro, se hacía una llama; de ambos

más ardiente era que antes, y dulcemente se hizo un susurro. Para no parecerte muy indiscreta, querida Luna, diría que se hizo todo: de amor las ansias, juntos calmamos. Y ni él me hizo reproches en el pasado de cosa alguna, ni yo tampoco a Delfis. Mas hoy a casa llegó la madre 
de Melixo y Filista, nuestra flautista no ha mucho tiempo; llegó, seré precisa, cuando hacia el cielo corrían las yeguas del Sol llevando a Aurora de brazos rosa desde el océano; me dijo, entre otras cosas, que, sí, que Delfis anda en amores; si la pasión de un joven o de una moza lo tiene ahora, decía no estar segura, pero sí de esto: siempre con vino puro de Eros brindaba; que, terminando, salía corriendo, diciendo ir a cubrirle la casa aquella con sus guimaldas. Me declaró estas nuevas la visitante, que nunca miente. Pues, cierto, en otro tiempo, tres, cuatro veces venía a mi casa diario, y aquí dejaba siempre su dorio frasco de aceite; hoy son ya doce días; mis ojos tristes no lo han mirado. ¿Quizá goza otros brazos, y hoy de nosotras ya se ha olvidado? ¡A hora voy a embrujarlo con estos filtros! Si aún me angustia, él pronto irá a llamar, juro a las Moiras, la puerta de Hades; afirmo reservarle dentro de un arca fuertes venenos, mortales, que he aprendido de un extranjero de Asiria, diosa. Mas tú, llena de encanto, vuelve tus potras hacia el Océano; yo llevaré, señora, mi pena a cuestas, como hasta ahora. ¡Adiós, gran diosa Luna de trono argénteo! ¡Adiós, las otras estrellas, que la noche callada siguen cerca del carro!

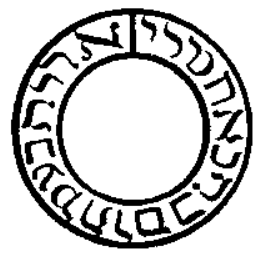

